\title{
Contribution from optical course for the educational guidance of engineering careers students
}

R. Toledo, I. Pérez, A. Yeras, J. J. González, D. Pareja, et al.

R. Serra Toledo, I. Alfonso Pérez, A. Moreno Yeras, J. J. Llovera González, D. Zottola Pareja, D. S. F. Magalhães, J. B. Lemus Alarcón, M. Muramatsu, "Contribution from optical course for the educational guidance of engineering careers students," Proc. SPIE 9289, 12th Education and Training in Optics and Photonics Conference, $92890 Z$ (17 July 2014); doi: 10.1117/12.2070747

Event: 12th Education and Training in Optics and Photonics Conference, 2013, Porto, Portugal 


\title{
Contribution from optical course for the educational guidance of engineering careers students
}

\author{
R. Serra Toledo ${ }^{\mathrm{a}}$, I. Alfonso Pérez ${ }^{\mathrm{a}}$, A. Moreno Yeras ${ }^{\mathrm{a}}$, J. J. Llovera González ${ }^{\mathrm{a}}$, D. Zottola Pareja ${ }^{\mathrm{a}}$, \\ D. S. F Magalhães ${ }^{\mathrm{b}}$, J.B. Lemus Alarcón ${ }^{\mathrm{c}}$, M. Muramatsu ${ }^{\mathrm{d}}$

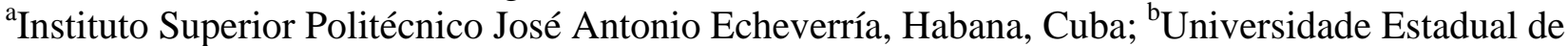 \\ Campinas, SP, Brasil; ' Universidad Libre de Colombia, Bogotá, Colombia; ${ }^{\mathrm{d}}$ Instituto de Física da \\ Universidade de São Paulo, SP, Brasil.
}

\begin{abstract}
The work shows the fundamental elements of an inclusive educational guidance conception of substantive university processes and results achieved at the Instituto Superior Politécnico José Antonio Echeverría of Havana in the contribution from optical course to develop it for the students in first and second year of the engineering programs, by means of lectures on holography and three-dimensional images of motivation and link with different specialties and the development of experimental facilities and methodology for the construction of holograms and anaglyph by students for engineering applications.
\end{abstract}

Keywords: physics, educational guidance, optics education, engineering

\section{INTRODUCTION}

Counseling is a process that has accompanied the various societies, cultures, families and individuals from the origins of humanity. From the first years of life are receiving guidance activities, and are family and school groups involved in it especially hard. In this sense, Collazo and Bridges point out that "the need for guidance, present throughout life, is essential in the early stages of formation and development of personality and in those moments when the person finds it difficult to decision making and do not feel adequately prepared for it " $"$.

Orientation is an essential element of the educational process in higher education and should not be understood as a complementary activity to the academic. It is considered one of the functions of the teacher who besides teaching the particularities of their discipline to be recognized as guiding ${ }^{2}$.

The teacher should move this context what is proper guidance in general (aid process, individualized, whole-person development, personal fulfillment, etc.) always taking into account the nature of education and its students ${ }^{3}$.

From the European Guidance Forum Academic Echeverria (1997) has defined the orientation at the university as "an educational process aimed at young people to gain an awareness hermeneutics, able to face a lot of informative inputs, to develop their own projects of personal and professional life, with specific regard to their own experiences and contrasted with social demans" ${ }^{4}$.

Some authors consider psychoeducational intervention that aims to fully develop students to achieve their academic goals, vocational and personal, others assume it as a helping process embedded in the educational activity which aims to contribute to the overall development of the student, to enable him to independent learning and active participation, critical and transforming society in ${ }^{5,6}$.

Vieira and Vidal (2006) assume it as "... the process of aid aimed at university students in academic, professional and personal in the context of higher education institutions. (...) should be understood as a system of guidance and student

12th Education and Training in Optics and Photonics Conference, edited by

Manuel F. P. C. Martins Costa, Mourad Zghal, Proc. of SPIE Vol. 9289, 92890Z

(C) 2014 SPIE, OSA, IEEE, ICO · doi: 10.1117/12.2070747

Proc. of SPIE Vol. 9289 92890Z-1 
support institutionally planned and organized response, both trends in higher education system, as to the peculiarities of each institution"7.

That is why the basis of the above, for these authors is transcendental idea of considering the relationship of assistance under a training process that contributes to the knowledge of the student and their environment, and lead to the development of his personality. We believe that the university is vital educational guidance to the student of the first years of our careers in engineering and helps to raise their professional motivation, an essential element of our proposal.

Without doubt, the definitions cited above reveal essential aspects of orientation at the university level, yet these authors consider necessary to point out the following:

- The university educational counseling should be part of the educational process in college, planned and organized on its merits and regulations established by higher courts.

- Establish a helping relationship and systematically provided to all students in the training process.

- Consolidate from the class considered as the fundamental unit of the training process, and one of the main ways of providing personal attention to the student in all essential processes of university life.

- Be based on the concept of integrating actions from taxing essential processes in the formation of the student.

Given these details we can say that the university educational guidance should be a reference for improving the teachinglearning process, not being considered as a task outside the educational work, which would imply a change in the traditional concept guidance that would be linked to a remedial approach and timely to move to deal with a helping process conducted by the entire university.

It is then necessary for students to learn how the interaction with others through collaborative processes such as: work in teams, they can also get solutions to academic difficulties, personal and professional are presented. This will appeal to that target not only the particularities of their profession but also for them to reach a general culture that enables them to provide answers from the professional, personal and social, without being divorced from the reality that live ${ }^{8}$.

Therefore, the orientation must be fully integrated into the educational process as it promotes quality education and helps develop the personality of students. The university stage is a momentous time for the student in which to make decisions that transcend life, why it is necessary to accompany him.

Monge, $C^{5}$ has suggested that educational guidance is an inseparable element of education to provide technical advice and support in more individualized aspects of it, and therefore contributes to a comprehensive education and the task of every teacher.

Assuming this idea is considered that the professor can and should make educational guidance activities with students as part of their work, of course, based on adequate preparation. When the teacher, through its communication and everyday example becomes a point of reference for the student, and encourages their independence and ability to address the issues presented to it and make decisions, it can be stated that the teacher is fulfilling its guiding function. In recent years we have been pointing out the mission of the universities and the relationship between the main processes developed. Diaz, T. ${ }^{9}$ and Gonzalez, G. ${ }^{10}$ have argued that if we consider the university as a social institution whose mission is to transform society, is critical processes conceive training, research and professional development as a single integrated training process aimed at solving social needs.

These authors have carried out an analysis of the main problems for the social relevance of universities and universitysociety relations summarize below:

- The practice of social problems are analyzed and starting point for the design of the educational process.

- Lack of integration between components academic and research work.

- Emphasis on instructional training over the educational and developmental.

- Deficiencies in the humanistic education of professionals.

- Slow responsiveness to social problems by professionals.

Given the points made above, these authors have pointed out two very important features that should meet your criteria university XXI century: 
- Formation, Research and University Extension must be integrated into a single task, applied to the solution of social needs.

- Must be a forger of conscious and responsible citizens, equipped with scientific and humanistic culture capable of forming themselves followed.

Recent publications refer to the need for new designs for teaching physics in the theoretical-conceptual and methodological, and should consider the progress of science in teaching practice and conducive to active student participation in the construction of knowledge within educational guidance work in college ${ }^{11}$.

This paper shows the results obtained at the Instituto Superior Politecnico Jose Antonio Echeverria in the contribution from physical discipline to the development of an educational concept that integrates essential processes designed for students in the early years in our engineering programs.

\section{IMPLEMENTATION OF THE PROPOSAL}

Within the educational conception substantive integrative processes designed for students in the early years in our engineering programs has a major role actions to be performed from the subjects of the basic cycle and in particular from physical discipline.

Physical discipline actions devised a system within which highlights the didactic proposal of conducting scientific work student as part of the improvement of the teaching-learning process of physical discipline in Biomedical Engineering Career ${ }^{12}$ and those shown in this paper: conducting lectures on holography and three-dimensional images of motivation and bond with different specialties and the development of experimental facilities and methodology for the construction of holograms and anaglyph by students for engineering applications.

\subsection{Lectures on holography and three-dimensional images}

Among the extracurricular activities that develop educational guidance for physical discipline in our engineering programs is the delivery of lectures on holography and three-dimensional images for students of the first two years, including observation of holograms and anaglyph built in Cuba.

This type of conference has the following objectives:

- Show phenomena of physics and applications related to three-dimensional vision very interesting and current.

- Increase motivation and physical discipline by different engineering careers.

- Show the link between physics and different specialties.

- Increase the interest of students in scientific research.

- Show the progress achieved in the country in relation to the development of holography and anaglyph and applications engineering.

These conferences have been held in the last four years to groups of students in the first and second years of different specialties, especially in biomedical engineering, civil engineering, hydraulic engineering and telecommunications engineering with good results of assistance, interest and motivation. In Figure 1 shows one of the activities in biomedical engineering students. 


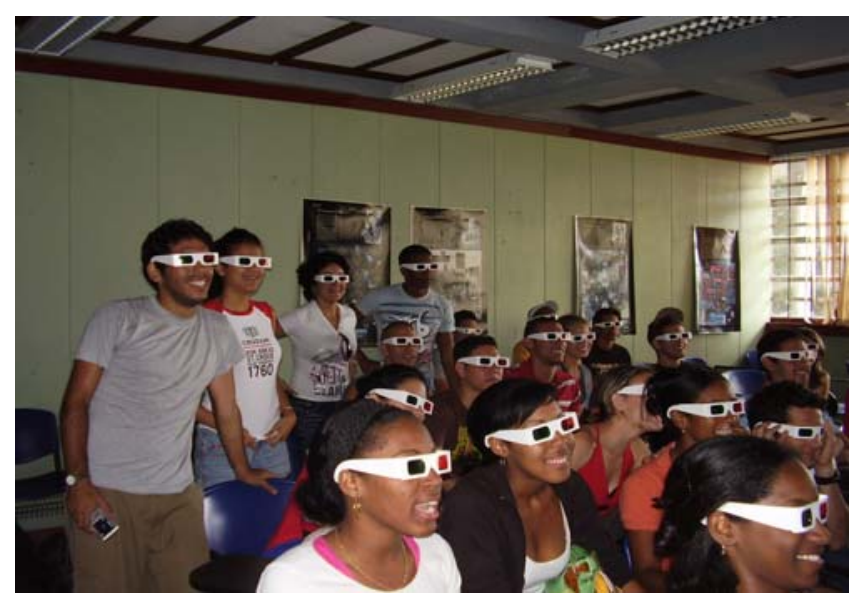

Figure 1. 3D image lecture to students of first year of biomedical engineering

Another variation of this activity has been the teaching of this conference in an educational exhibition of holography as shown in Figure 2.

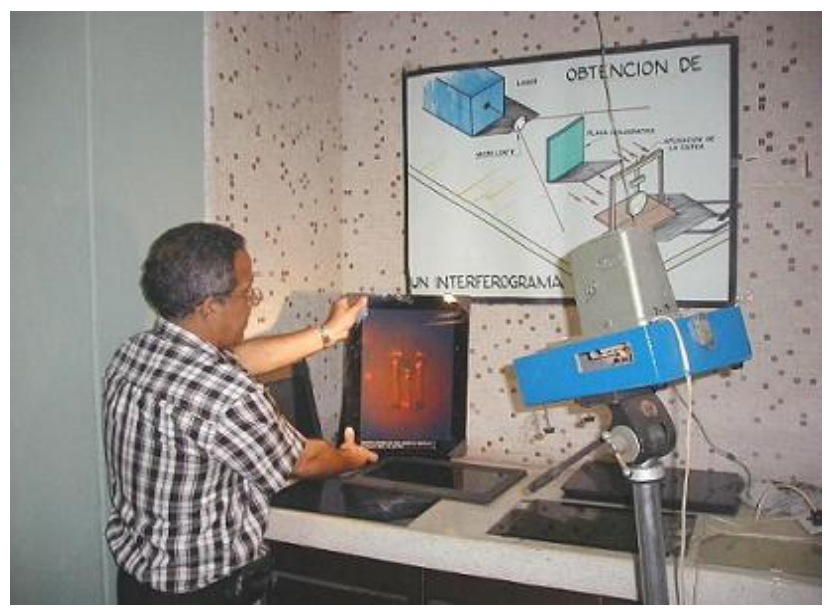

Figure 2. Activity in the didactics holography exhibition

\subsection{Construction of holograms by students}

The development of new educational proposals for the design and use of systems experiments on different forms of learning of physical discipline, including the use of new technological devices developed recently in the world, is of great importance as a contribution to achieving increase understanding of the laws and concepts studied, motivation and development of practical skills and observation in the learning of the discipline ${ }^{13}$.

The holograms may be constructed with the use of laser pointers that are manufactured with laser diodes emitting in the visible spectrum, making feasible their use in the learning of the University Physics and particularly the optic ${ }^{14}$, their great advantages over conventional gas lasers such as He-Ne high cost and difficult handling (See Fig 3).

For obtaining holograms are constructed as an experimental facility shown in Figure 4. The closed box, which prevents entry of any external light is placed on two small chambers bicycles that allow the isolation of the system from any external vibration.

Then in Figure 5 shows the results obtained in the obtainment of a hologram with this experimental installation: 


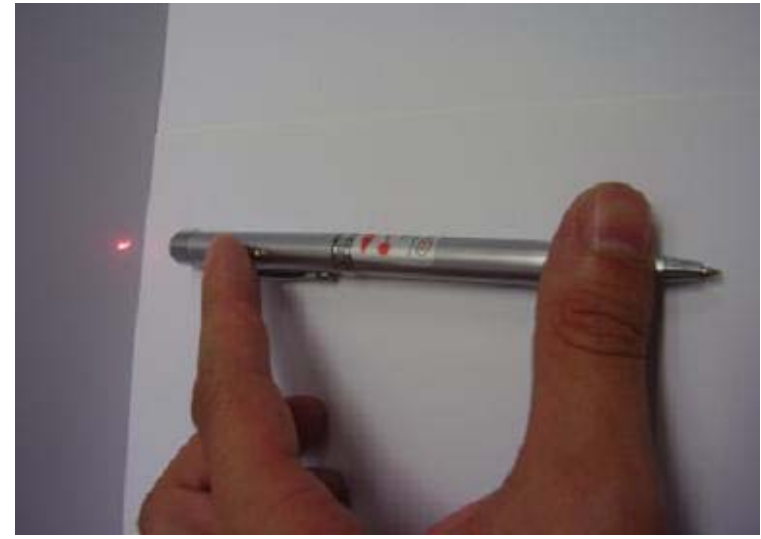

Figure 3. Laser pointer used for obtaining the holograms

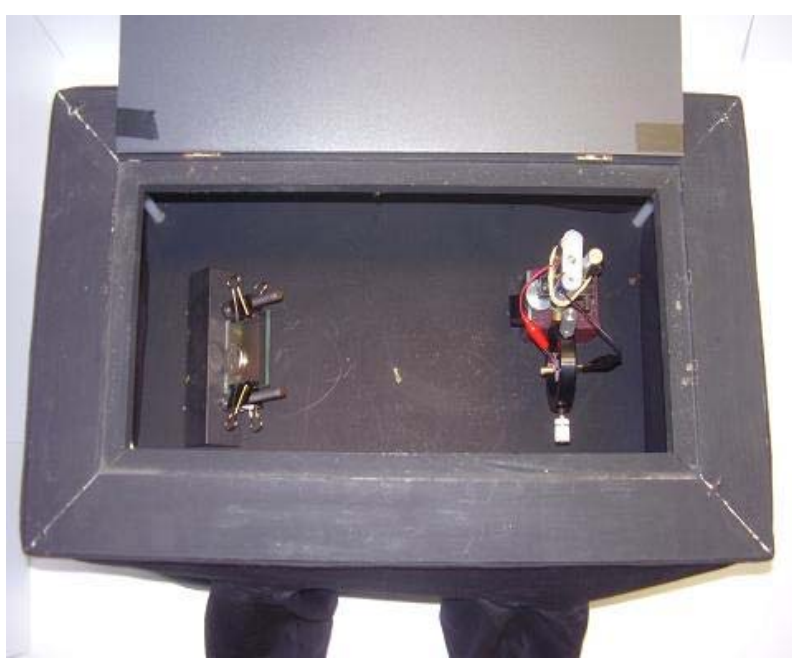

Figure 4. Experimental setup for obtaining holograms

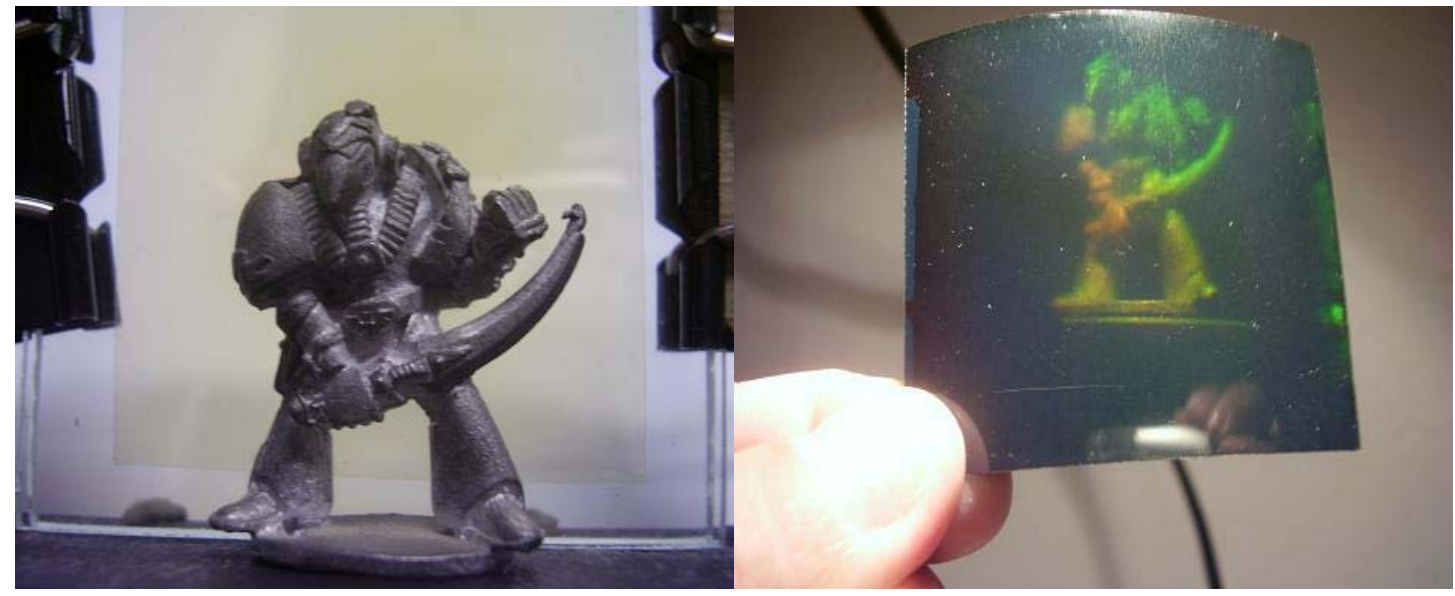

Figure 5. The object and the hologram obtained

Proc. of SPIE Vol. 9289 92890Z-5

Downloaded From: https://www.spiedigitallibrary.org/conference-proceedings-of-spie on 26 Apr 2023 Terms of Use: https://www.spiedigitallibrary.org/terms-of-use 


\subsection{Construction of anaglyph by students}

In the teaching of engineering careers, study materials containing images loaded with a variety of ancillary techniques to help better understand dimensions, relative positions, etc.. It is required in many cases of three-dimensional images that are helpful and allow a better understanding of the issues introduced because the depth information.

Second year students of biomedical engineering and civil engineering with physics teachers; have developed an extracurricular research work that has allowed obtaining anaglyph for applications in these specialties ${ }^{15}$.

The records dimensional anaglyphs are capable of causing a three dimensional effect when viewed using glasses of two colors (mostly red and green or red and blue). The plane images through which the anaglyph is obtained are relatively different. In the case where the images are photographs, must be obtained so that they are spaced apart a distance approximating the inter-ocular separation media. Once the images forming the stereo pair are obtained, they must be processed by a computer program which will perform the filtering of these two images in the colors indicated and are then superimposed to give the end anaglyph (see Figure 6) that the be seen with special glasses described above allow the brain to form a three-dimensional image.

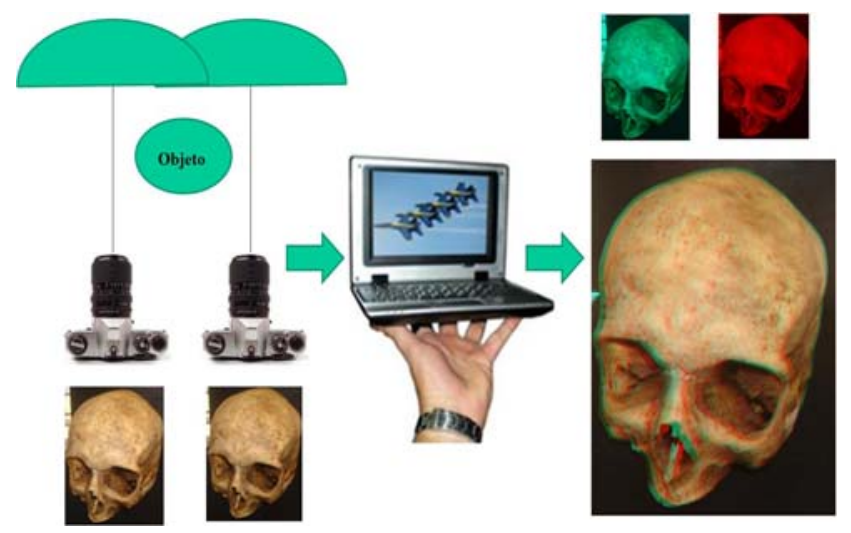

Figure 6. Representation of the necessary steps for obtaining anaglyphs

To obtain the anaglyph, was developed in Matlab software offered as simple as possible to the user (see Figure 7)

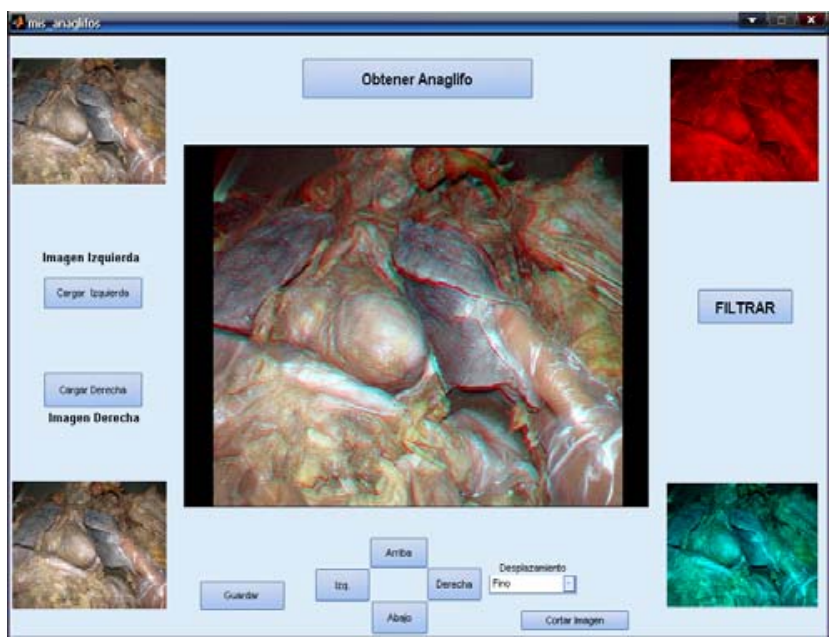

Figure 7. Software interface developed

Below you can see anaglyph obtained by students for medical and civil engineering (Figures 8 and 9): 


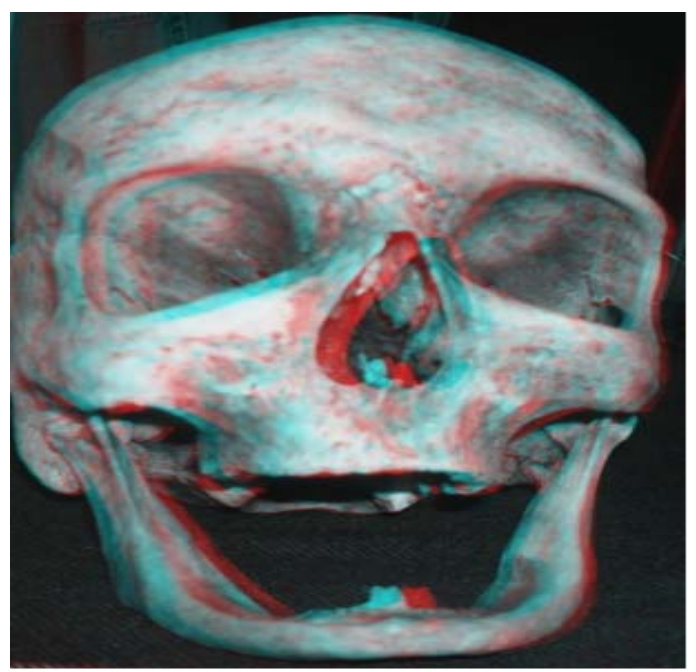

Figure 8 - Anaglyph of an anatomical preparation

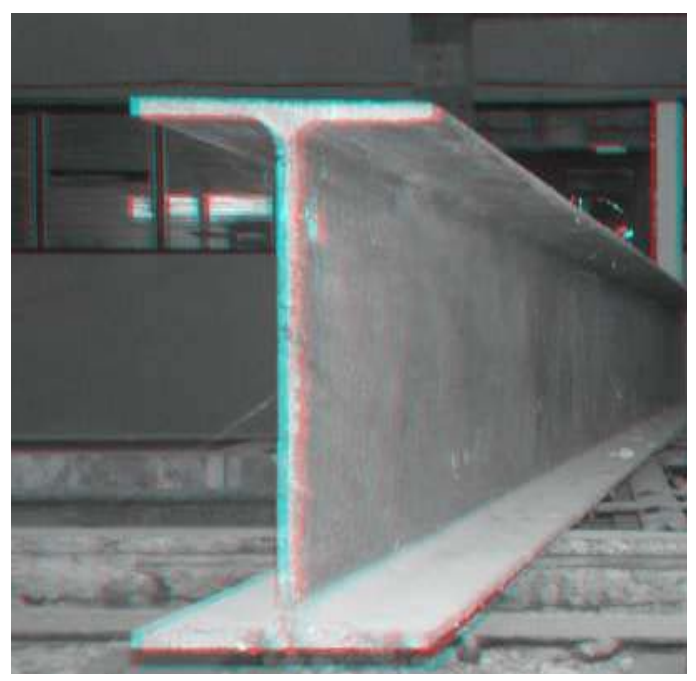

Figure 9 - Anaglyph of a beam

\section{CONCLUSIONS}

We analyzed the main elements of a concept of integrating educational guidance of the substantive university processes and results achieved at the Instituto Superior Politécnico Jose Antonio Echeverría of Havana in the contribution from physical discipline to develop it for students of one and second year of the engineering programs, by conducting lectures on holography and three-dimensional images of motivation and link with different specialties and the development of experimental facilities and methodology for the construction of holograms and anaglyph by students for applications engineering.

Was presented the design and construction of a portable experimental installation designed for the manufacture of holograms using a diode laser pointer. This facility allows the realization of holograms by students at school or even at 
home, promoting better understanding of the laws and concepts of physics and in particular the related optics holographic process and also contributes to increasing the motivation of students in this discipline.

Research on the construction of anaglyphs with results presented was developed by students in the second year of biomedical engineering and civil engineering careers, demonstrating the potential of the student scientific work to get the anaglyph first built in the country for engineering applications.

\section{REFERENCES}

[1] Collazo, B. y Puentes, M., [La orientación en la actividad pedagógica ¿el maestro, un orientador?], Editorial Pueblo y Educación, La Habana, (1992).

[2] Collazo, B., [Modelo de tutoría integral para la continuidad de estudios universitarios en las sedes municipales], Tesis de doctorado, Cuba, (2006).

[3] Rodríguez, S., [Orientación universitaria y evaluación de la calidad. Calidad de la universidad: orientación y evaluación], Apodaca, P. y C. Lobato (Eds.), Barcelona, Laertes, (1997).

[4] Echeverría, B., [Los servicios de orientación universitarios. Calidad en la universidad: orientación y evaluación], Apodaca, P. y C. Lobato (Eds.), Barcelona: Laertes, 112-136, (1997).

[5] Monge, M.C., [Tutoría y orientación educativa. Nuevas competencias], Las Rozas, Wolters Kluwer, (2009).

[6] Santana, L.E., [Orientación educativa e intervención psicopedagógica cambian los tiempos, cambian las responsabilidades profesionales], Pirámide, Madrid, (2009).

[7] Vieira, M.J. y Vidal, J., “Tendencias de la Educación Superior Europea e implicaciones para la orientación universitaria”, Revista española de orientación y psicopedagogía, 17(1), 75-97, (2006).

[8] Jaime, R.A., "La orientación educativa como tarea inseparable de la Extensión Universitaria", Revista Cuadernos de Educación y Desarrollo, 3(28), (2011).

[9] Díaz, T., "La Extensión: Un proceso formativo de la Universidad. Su relación con otros procesos”, Conferencia Magistral del VI Taller Internacional de Extensión Universitaria, Memorias, Cuba, (2001).

[10] González, G., "Extensión Universitaria: Una visión, un cambio necesario”, Conferencia de la III Convención Internacional de Educación Superior, Memorias, Cuba, (2002).

[11] Oliveira, N., "The notorial dynamic analisis of an artificial satellite: a pedagogical experiment in space education”, Revista Brasileira de Ensino de Física, 30(1), 1401, (2008).

[12] Serra, R., Alfonso, I., Herrera, R., Ferreira, D., Muramatsu, M., Soga, D., "La física y el trabajo científico estudiantil en la formación del ingeniero biomédico”, enviado a LAJFE en proceso de arbitraje, enero, (2013).

[13] Serra, R., [La utilización del holograma como medio de enseñanza y de educación social en Cuba a través del vínculo Investigación -Docencia -Extensión Universitaria], Tesis Doctoral, Cuba, (2004).

[14] Serra, R., Moreno A., Magalhães, D., Muramatsu M., Lemus J., "Haciendo hologramas en la escuela y en la casa”, Revista Brasileira de Ensino de Física 32(3), 3502 (2010).

[15] Zottola, D., Hernández, A., Serra, R., “Anaglifos en la enseñanza de la ingeniería biomédica”, Proc. of V Latin American Congress on Biomedical Engineering, Habana, (2011). 